\title{
Galleria mellonella as an infection model for Campylobacter jejuni virulence
}

Correspondence

Richard W. Titball

R.W.Titball@exeter.ac.uk

Received 29 September 2010 Accepted 11 January 2011

\author{
Nicola J. Senior, ${ }^{1}$ Mary C. Bagnall, ${ }^{2}$ Olivia L. Champion, ${ }^{1}$ \\ Stuart E. Reynolds, ${ }^{3}$ Roberto M. La Ragione, ${ }^{2,4}$ Martin J. Woodward, ${ }^{2}$ \\ Francisco J. Salguero ${ }^{2}$ and Richard W. Titball ${ }^{1}$ \\ ${ }^{1}$ School of BioSciences, College of Life and Environmental Sciences, University of Exeter, \\ Geoffrey Pope Building, Stocker Road, Exeter, UK \\ ${ }^{2}$ Veterinary Laboratories Agency, Woodham Lane, Addlestone, UK \\ ${ }^{3}$ Department of Biology and Biochemistry, University of Bath, Bath, UK \\ ${ }^{4}$ Faculty of Health and Medical Sciences, University of Surrey, Guildford, UK
}

\begin{abstract}
Larvae of Galleria mellonella (Greater Wax Moth) have been shown to be susceptible to Campylobacter jejuni infection and our study characterizes this infection model. Following infection with C. jejuni human isolates, bacteria were visible in the haemocoel and gut of challenged larvae, and there was extensive damage to the gut. Bacteria were found in the extracellular and cell-associated fraction in the haemocoel, and it was shown that C. jejuni can survive in insect cells. Finally, we have used the model to screen a further $67 \mathrm{C}$. jejuni isolates belonging to different MLST types. Isolates belonging to ST257 were the most virulent in the Galleria model, whereas those belonging to ST21 were the least virulent.
\end{abstract}

\section{INTRODUCTION}

Campylobacter jejuni is recognized as the leading cause of bacterial gastroenteritis across the developed world; the World Health Organization estimates that $1 \%$ of the population of Western Europe is infected with campylobacters each year. It is thought that for each reported case, a further nine go unreported (Humphrey et al., 2007), thus, based on the reported figures for 2009 from the Health Protection Agency, this would mean that there were in excess of 500000 cases in England and Wales alone. Furthermore, beyond the initial diarrhoeal disease, C. jejuni may also cause post-infection complications including irritable bowel syndrome, meningitis and Guillain-Barré syndrome plus its variant Miller Fisher syndrome (Janssen et al., 2008; van Doorn et al., 2008).

Despite having been first identified as a causative agent of diarrhoea in 1977 (Skirrow, 1977), C. jejuni pathobiology remains poorly understood, with its core virulence determinants remaining elusive. A major contributing factor in the lack of determination of these factors has been the absence of a suitable infection model for $C$. jejuni. Previous models have included a ferret diarrhoeal model (Fox et al., 1987), a chick colonization model (Wassenaar et al., 1993) and a colostrum-deprived piglet model (Babakhani et al., 1993). However, in common with other mammalian and

Abbreviations: GFP, green fluorescent protein; H\&E, haematoxylin and eosin; MLST, multilocus sequence typed. avian models, their widespread use has been limited by factors such as cost, ease of use, reproducibility and ethics (Newell, 2001).

We recently reported that larvae of the lepidopteran insect Galleria mellonella (Greater Wax Moth) are susceptible to infection by $C$. jejuni and can be used to screen for virulence genes (Champion et al., 2010). In this study, we aimed to characterize G. mellonella as a C. jejuni infection model and to screen a panel of multilocus sequence typed (MLST) C. jejuni field isolates for virulence in $G$. mellonella. Different MLST groups were chosen to cover types detected in the main food-producing animals, the environment and clinical disease.

\section{METHODS}

Strains and cultures. All bacterial strains and mutants used in this study are shown in Table 1. C. jejuni strain $11168-\mathrm{H}$ is a hypermotile variant of the sequenced strain NCTC 11168 that readily colonizes chickens (Jones et al., 2004; Karlyshev et al., 2002). C. jejuni strains were cultured on either blood agar Skirrows actidione (BASA) plates or Columbia agar plates (CBA) supplemented with $5 \%(\mathrm{v} / \mathrm{v})$ horse blood in anaerobic jars in an atmosphere of $6 \% \mathrm{O}_{2} / 10 \% \mathrm{CO}_{2}$ (CampyPak; Oxoid) for $48 \mathrm{~h}$ at $37^{\circ} \mathrm{C}$.

For infections, bacteria were subcultured into $6 \mathrm{ml}$ Mueller-Hinton $(\mathrm{MH})$ broth (Oxoid) and grown under microaerobic conditions for $24-48 \mathrm{~h}$ at $37{ }^{\circ} \mathrm{C}, 150$ r.p.m. The bacteria were then adjusted to $\mathrm{OD}_{590} 1.0$ in PBS (0.1 M, pH 7.2) for infections, equivalent to $1 \times 10^{8}$ c.f.u. $\mathrm{ml}^{-1}$. Infections at lower doses were adjusted accordingly. 
Table 1. Bacterial strains used in this study

\begin{tabular}{|c|c|c|}
\hline Strain & Origin & MLST group \\
\hline $11168-\mathrm{H}$ & Human & ST43/CC21 \\
\hline $11168-\mathrm{O}$ & Human & ST43/CC21 \\
\hline pREM5 11168H & Human & ST43/CC21 \\
\hline 81116 & Human & ST267/CC283 \\
\hline 81176 & Human & ST913/CC42 \\
\hline $01 / 51$ & Human & ST626/CC21 \\
\hline $01 / 43$ & Human & ST257/CC257 \\
\hline $93 / 372$ & Pet & ST21/CC21 \\
\hline $94 / 229$ & Poultry & ST45/CC45 \\
\hline $99 / 97$ & Human & ST45/CC45 \\
\hline $99 / 118$ & Cow & ST21/CC21 \\
\hline $99 / 188$ & Human & ST21/CC21 \\
\hline $99 / 189$ & Human & ST45/CC45 \\
\hline $99 / 194$ & Cow & ST45/CC45 \\
\hline $99 / 197$ & Human & ST45/CC45 \\
\hline $99 / 201$ & Cow & ST48/CC48 \\
\hline $99 / 202$ & Cow & ST45/CC45 \\
\hline $99 / 212$ & Human & ST45/CC45 \\
\hline $99 / 216$ & Human & ST45/CC45 \\
\hline $99 / 242$ & Poultry & ST45/CC45 \\
\hline $\mathrm{A} 1 / \mathrm{CF} / 12$ & Poultry & ST257/CC257 \\
\hline $\mathrm{A} 6 / \mathrm{T} 2 / 15$ & Poultry & ST257/CC257 \\
\hline A8/35/15A & Poultry & ST257/CC257 \\
\hline $\mathrm{C} 1 / \mathrm{C} / 2$ & Poultry & ST257/CC257 \\
\hline $\mathrm{C} 120 / 2$ & Poultry & ST257/CC257 \\
\hline $\mathrm{C} 132 / 1$ & Poultry & ST19/CC21 \\
\hline $\mathrm{C} 3 / \mathrm{T} / 25$ & Poultry & ST257/CC257 \\
\hline $\mathrm{C} 5 / \mathrm{T} 2 / 8$ & Poultry & ST257/CC257 \\
\hline C85-4-99-5 & Cow & ST262/CC21 \\
\hline C500-1-99-2 & Cow & ST48/CC48 \\
\hline C559-3-99-2 & Cow & ST262/CC21 \\
\hline $\mathrm{D} 2 / 27 / 3$ & Poultry & ST48/CC48 \\
\hline $\mathrm{D} 2 / \mathrm{T} / 8$ & Poultry & ST48/CC48 \\
\hline $\mathrm{D} 2 / \mathrm{T} / 95$ & Poultry & ST48/CC48 \\
\hline D5-20-9A & Poultry & ST262/CC21 \\
\hline EX1182 & Environmental & ST262/CC21 \\
\hline EX1286 & Poultry & ST262/CC21 \\
\hline MB1 & Poultry & ST48/CC48 \\
\hline MB2 & Poultry & ST48/CC48 \\
\hline MB3 & Poultry & ST48/CC48 \\
\hline MB4 & Poultry & ST19/CC21 \\
\hline MB5 & Poultry & ST19/CC21 \\
\hline MB6 & Poultry & ST19/CC21 \\
\hline MB7 & Poultry & ST262/CC21 \\
\hline MB8 & Poultry & ST48/CC48 \\
\hline MB9 & Poultry & ST257/CC257 \\
\hline MB10 & Poultry & ST19/CC21 \\
\hline MB12 & Poultry & ST21/CC21 \\
\hline MB13 & Poultry & ST21/CC21 \\
\hline MB14 & Poultry & ST21/CC21 \\
\hline MB15 & Poultry & ST45/CC45 \\
\hline MB16 & Poultry & ST48/CC48 \\
\hline MB17 & Poultry & ST262/CC21 \\
\hline MB18 & Poultry & ST21/CC21 \\
\hline Ps308 & Pig & ST51/CC403 \\
\hline Ps549.1 & Pig & ST403/CC403 \\
\hline
\end{tabular}

Table 1. cont

\begin{tabular}{|lll|}
\hline Strain & \multicolumn{1}{c|}{ Origin } & MLST group \\
\hline Ps623 & Pig & ST552/CC403 \\
Ps762 & Pig & ST270/CC403 \\
Ps830 & Pig & ST403/CC403 \\
Ps838 & Pig & ST403/CC403 \\
Ps843 & Pig & ST403/CC403 \\
Ps849 & Pig & ST403/CC403 \\
Ps852 & Pig & ST270/CC403 \\
Ps857 & Pig & ST270/CC403 \\
S39-2-99-3 & Sheep & ST21/CC21 \\
S87-4-99-3 & Sheep & ST262/CC21 \\
S120-4-99-4 & Sheep & ST45/CC45 \\
S216-5-99-1 & Sheep & ST257/CC257 \\
S372-5-99-4 & Sheep & ST21/CC21 \\
S379-8-99-1 & Sheep & ST262/CC21 \\
S435-3-99 & Sheep & ST262/CC21 \\
S499-1-99-5 & Sheep & ST19/CC21 \\
S585-3-99 & Sheep & ST19/CC21 \\
\hline
\end{tabular}

G. mellonella virulence assays. G. mellonella larvae were purchased from Live Foods UK and maintained on wood chips at $15{ }^{\circ} \mathrm{C}$. The infection of larvae was carried out as previously described (Champion et al., 2010) using a micro-injection technique whereby $10 \mu \mathrm{l} \mathrm{C}$. jejuni was injected into the haemocoel via the right foreleg, using a Hamilton syringe. Larvae were then incubated at $37{ }^{\circ} \mathrm{C}$ and survival and macroscopic appearance were recorded at $24 \mathrm{~h}$ postinfection. PBS injected and uninfected controls were used. For each, experimental groups of ten G. mellonella larvae were infected.

Association of C. jejuni with haemocytes. A group of three G. mellonella larvae was infected as above with $10^{6}$ c.f.u. of C. jejuni $11168-\mathrm{H}$ and incubated at $37{ }^{\circ} \mathrm{C}$ for $24 \mathrm{~h}$. The larvae were chilled on ice for $20 \mathrm{~min}$ before aseptic removal of the bottom $2 \mathrm{~mm}$ of the body. The haemocoel was drained from each larva into sterile microcentrifuge tubes and centrifuged at $200 \mathrm{~g}$ for $5 \mathrm{~min}$. The supernatant, which was the haemolymph, was transferred to a separate sterile microcentrifuge tube. The pelleted haemocytes were resuspended in $100 \mu \mathrm{l}$ sterile distilled water, and pipetted up and down ten times to lyse the cells. Serial dilutions of both haemolymph and haemocytes were plated out on CBA to enumerate bacteria.

Histopathology. C. jejuni-infected and uninfected larvae (five per group) were fixed by immersion in $10 \%(\mathrm{v} / \mathrm{v})$ neutral buffered formalin for 3-7 days. For light microscopy, larvae were blocked by a longitudinal section dividing the animal into two pieces and smears were air-dried and stained with Gram-Twort. The larvae (20\%) were blocked into 11 transversal sections serially from the cranial to the caudal extremities of the larvae. Sections were embedded in paraffin wax and routinely stained with haematoxylin and eosin (H\&E) for microscopic examination.

Investigation of $\mathbf{C}$. jejuni morphology following infection of $\mathbf{G}$. mellonella. A green fluorescent protein (GFP)-tagged C. jejuni strain, pREM5 11168H GFP (donated by Andrey Karlyshev, Kingston University, Surrey, UK), was cultured under microaerobic conditions on $\mathrm{MH}$ agar. It was then subcultured into $\mathrm{MH}$ broth as before and incubated for $24 \mathrm{~h}$ at $37{ }^{\circ} \mathrm{C}$ under microaerobic conditions. An inoculum was prepared at $\mathrm{OD}_{590}$ as previously described above. Five G. mellonella larvae were infected with $10 \mu \mathrm{l}$ of the prepared inoculum, and a further five were inoculated with $10 \mu \mathrm{l}$ PBS. The larvae were incubated at $37^{\circ} \mathrm{C}$ for $3 \mathrm{~h}$ before being chilled on ice for 
$5 \mathrm{~min}$. They were then swabbed with $70 \%$ ethanol prior to the aseptic removal of the bottom $2 \mathrm{~mm}$ of the body as previously described. One of each larval set was drained separately; the other four of each set had their haemocoel combined. This combined haemocoel was centrifuged at $500 \mathrm{~g}$ for $5 \mathrm{~min}$ to pellet the haemocytes, and $10 \mu \mathrm{l}$ of the supernatant (haemolymph) was dropped onto a slide. A further $10 \mu \mathrm{l}$ from the non-centrifuged haemocoel and $10 \mu \mathrm{l}$ from the overnight $C$. jejuni culture were also dropped onto separate slides. Slides were examined using a Zeiss LSM 510 META confocal microscope.

Cell culture. J774A.1, a murine monocyte macrophage-like cell line, was obtained from the American Type Culture Collection (reference TIB-67), and cultured in Dulbecco's Modified Eagle Medium (from Fisher Scientific) supplemented with $10 \%$ fetal bovine serum at $37{ }^{\circ} \mathrm{C}$. SF9, a lepidopteran cell line, was donated by Richard ffrenchConstant (University of Exeter, UK), and cultured in Grace's Insect Medium (from Fisher Scientific) supplemented with $10 \%$ fetal bovine serum at $27^{\circ} \mathrm{C}$. The cells were seeded at $2 \times 10^{5}$ cells in 6 -well tissue culture plates and then incubated at the appropriate temperature for $24 \mathrm{~h}$ under $5 \% \mathrm{CO}_{2}$ prior to infection with C. jejuni.

Bacterial infection of cultured cells. C. jejuni $11168-\mathrm{H}$ was cultured on a CBA plate and harvested from an overnight culture by rolling a moistened swab over the plate; cells were resuspended in PBS. The $\mathrm{OD}_{590}$ was measured and the inoculum was prepared at a multiplicity of infection (m.o.i.) of 10 in L-15 medium (from Fisher
Scientific) before being added to both macrophages and insect cells (three replicates). The macrophages were incubated at $37^{\circ} \mathrm{C}$ for $1 \mathrm{~h}$; the insect cells were incubated at $27{ }^{\circ} \mathrm{C}$ for $1 \mathrm{~h}$. Following incubation, the inoculum in each well was replaced with L-15 medium containing $50 \mu \mathrm{g}$ gentamicin $\mathrm{ml}^{-1}$, and the plates were then incubated at the appropriate temperature for a further $1 \mathrm{~h}$. The medium was removed and the cells were incubated in L-15 containing $10 \mu \mathrm{g}$ gentamicin $\mathrm{ml}^{-1}$ for approximately $16 \mathrm{~h}$.

The cells were then washed three times with PBS, and $1 \mathrm{ml}$ cold sterile water was added to each well. The cells were mechanically lysed to release intracellular bacteria, and c.f.u. were determined after plating out serial dilutions on CBA plates and incubating microaerobically at $37^{\circ} \mathrm{C}$.

\section{RESULTS}

\section{C. jejuni induces histopathological changes in G. mellonella}

To better understand the fate of C. jejuni inoculated into G. mellonella, larvae challenged with $10^{6}$ c.f.u. of some wellcharacterized human isolates were fixed in neutral buffered formalin at $24 \mathrm{~h}$ post-infection and sectioned for histopathology. Fig. 1 shows H\&E-stained sections of uninfected
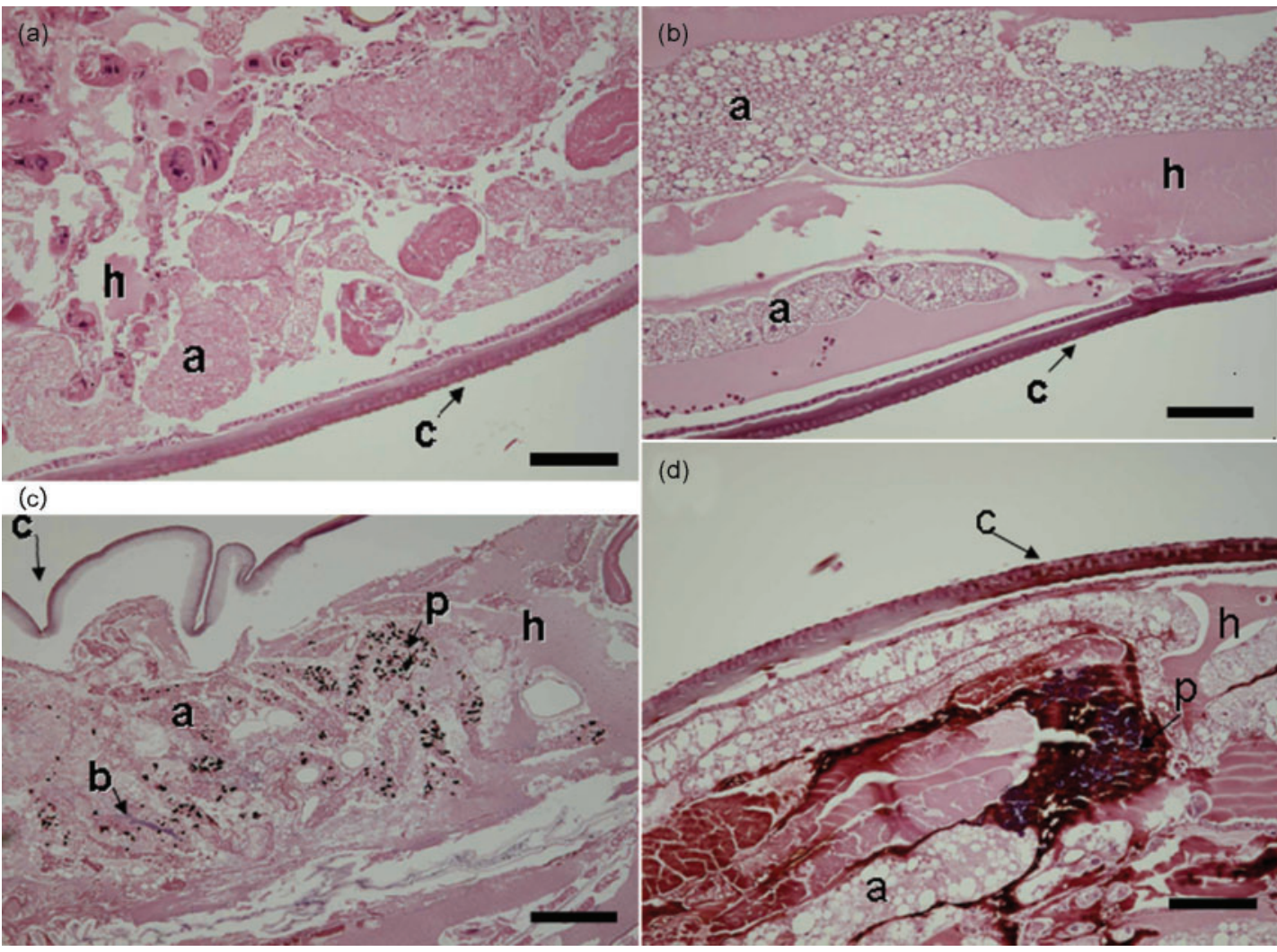

(d)

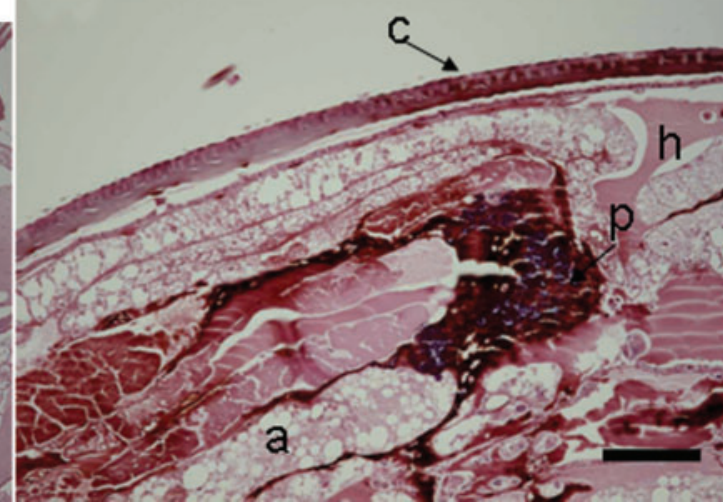

Fig. 1. H\&E-stained sections of G. mellonella. (a) Non-infected larva (bar, $100 \mu \mathrm{m})$; (b) control (0.1 M PBS inoculation) larva (bar, $100 \mu \mathrm{m}$ ); (c) larva infected with C. jejuni 81116 and incubated at $37{ }^{\circ} \mathrm{C}$ (bar, $250 \mu \mathrm{m}$ ); (d) larva infected with $\mathrm{C}$. jejuni 81116 and incubated at $42{ }^{\circ} \mathrm{C}$ (bar, $\left.100 \mu \mathrm{m}\right)$. Structures are annotated as follows: a, adipose bodies; b, bacterial colonies; c, cuticle; h, haemolymph; p, pigmented structures. 
and infected larvae. Bacteria were observed in the haemocoel and sections of gut from infected larvae, but were absent in sections from uninfected controls. There was evidence of damage to the midgut, with apoptotic cells and loss of integrity to the gut wall in the infected larvae. This damage was not visible in the control sections. Other tissues (fat body, muscle, nervous tissue) appeared undamaged in infected larvae and uninfected controls. Pigmented nodules were also present in infected larvae, and bacteria were associated with these nodules. These nodules were not visible in the uninfected control larvae.

The observed bacteria were coccoid rather than having the characteristic spiral form associated with $C$. jejuni. To investigate whether these coccoid bacteria were actually $C$. jejuni, G. mellonella larvae were infected with GFP-tagged C. jejuni; the haemocoel was collected and centrifuged at low speed to sediment haemocytes, which are often autofluorescent. Comparisons with C. jejuni from an overnight culture showed that these bacteria had the expected morphology, but bacteria in haemolymph were of a coccoid nature (Fig. 2). Similar observations of haemolymph from control larvae inoculated with PBS showed no fluorescence at all.

To investigate the site of replication, haemocoel was collected and centrifuged at low speed to sediment haemocytes. The number of bacteria found in the resuspended cell pellet $\left(4.1 \times 10^{6}\right.$ c.f.u.; SEM $\left.2.98 \times 10^{6}\right)$ was broadly similar to the number found in the haemolymph $\left(7.7 \times 10^{6}\right.$ c.f.u.; SEM $\left.2.3 \times 10^{6}\right)$.

A macro scoring system was used to examine whether there was a correlation between the colour of the larvae and the presence of bacteria in the gut or body cavity (Table 2; Fig. $3)$. There was a significant association between macro colour and the presence of bacteria in the body cavity $(P<0.001$, Kruskall-Wallis non-parametric test). No associations were made between the location of the bacteria and temperature at which they had been grown, or location and the strain of $C$. jejuni used to inoculate the larvae.

\section{An insect cell line and mammalian macrophages are comparable in their response to challenge with C. jejuni}

Insect (SF9) and mammalian (J774A.1) cells were infected at an m.o.i. of 10 with C. jejuni $11168-\mathrm{H}$, and monitored at $4 \mathrm{~h}$ and $24 \mathrm{~h}$ post-infection. In J774A.1 macrophages, bacterial numbers declined 100 -fold by $4 \mathrm{~h}$ post-infection (Fig. 4). However, the bacterial numbers then remained approximately constant in the macrophages at $24 \mathrm{~h}$ postinfection. There was a broadly similar pattern of survival in the SF9 cell line. Bacterial numbers decreased 1000-fold during the first $4 \mathrm{~h}$ of the infection, but there was an approximate 10-fold increase in bacterial numbers between $4 \mathrm{~h}$ and $24 \mathrm{~h}$ (Fig. 4). This increase was statistically analysed using a Student's $t$-test and found to be significant $(P<0.05)$.
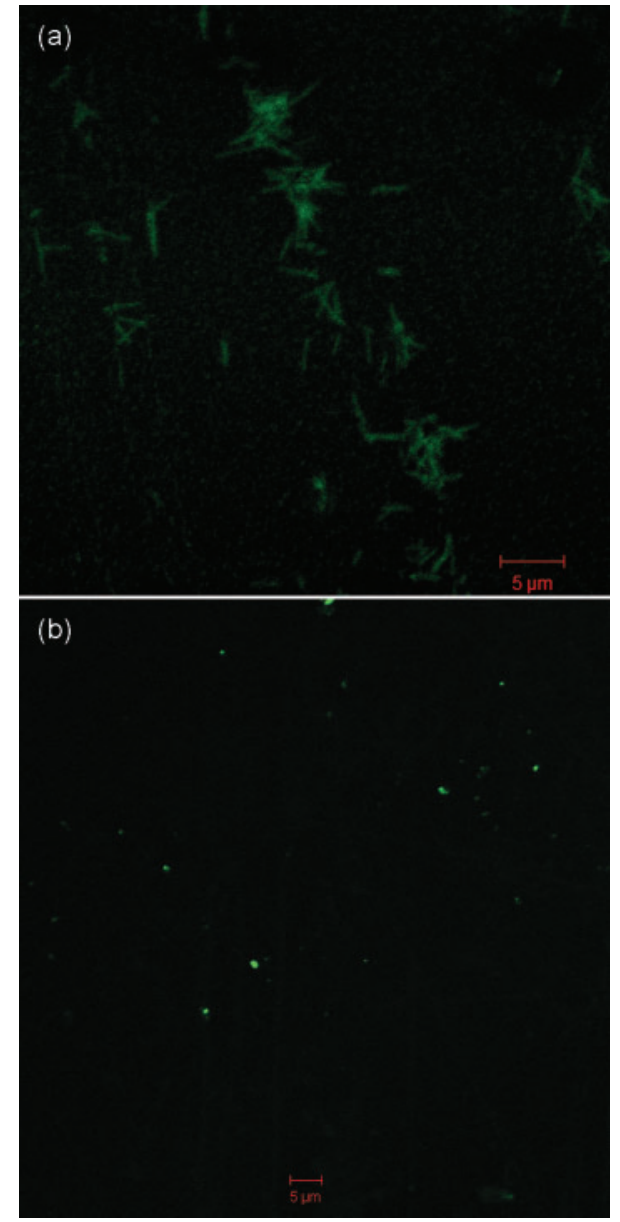

Fig. 2. Confocal microscope images of GFP-tagged C. jejuni pREM5 $11168 \mathrm{H}$. (a) C. jejuni from an overnight broth culture; (b) C. jejuni in the haemolymph of infected $G$. mellonella after a $3 \mathrm{~h}$ incubation.

\section{Differences in virulence were observed in G. mellonella between C. jejuni MLST complexes}

To investigate whether there was an association between MLST type and virulence, larval survival was recorded following challenge with $67 \mathrm{C}$. jejuni strains belonging to different MLST types (Fig. 5). It was observed that there was variation within MLST groups as well as between them. There was a significant difference $(P=0.0002)$ between the ability of ST21 and ST257 strains to cause disease. Overall, strains belonging to ST21 showed the least virulence in the model, whilst strains belonging to ST257 were the most virulent.

\section{DISCUSSION}

We have previously demonstrated that G. mellonella larvae can be used to screen for virulence of Campylobacter genes (Champion et al., 2010). In this study, we have characterized the G. mellonella model and demonstrated that it can 
Table 2. Macro scores for different $C$. jejuni strains in terms of colour, presence of bacteria in the larval gut and presence of bacteria in the larval body cavity

G. mellonella was incubated at different temperatures. A score of 3 for macro colour refers to fatality. ND, No data.

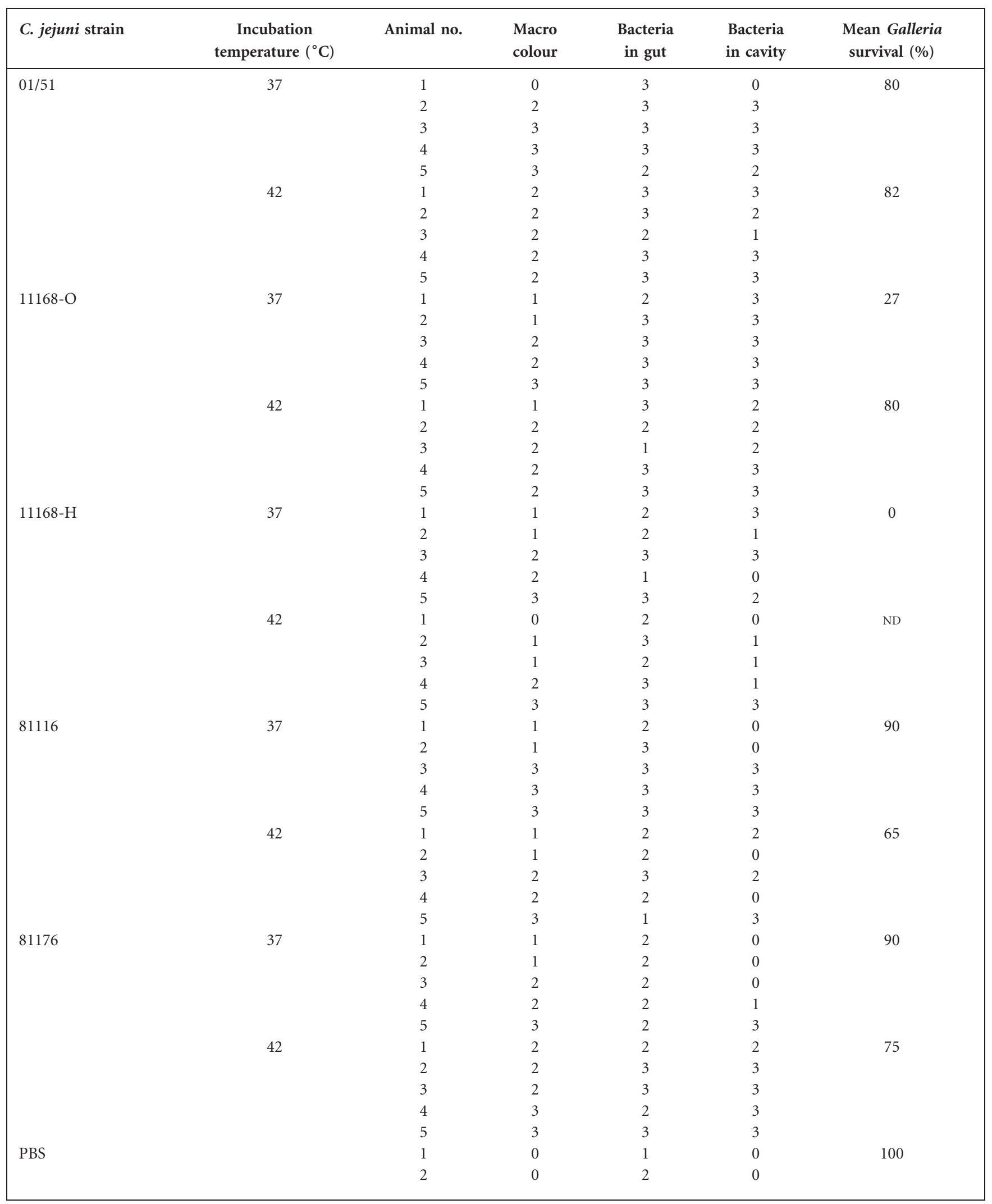


Table 2. cont.

\begin{tabular}{|lccccc|}
\hline C. jejuni strain & $\begin{array}{c}\text { Incubation } \\
\text { temperature }\left({ }^{\circ} \mathrm{C}\right)\end{array}$ & Animal no. & $\begin{array}{c}\text { Macro } \\
\text { colour }\end{array}$ & $\begin{array}{c}\text { Bacteria } \\
\text { in gut }\end{array}$ & $\begin{array}{c}\text { Bacteria } \\
\text { in cavity }\end{array}$ \\
\hline & 3 & 0 & 2 & 0 & $\begin{array}{c}\text { Mean Galleria } \\
\text { survival }(\%)\end{array}$ \\
& & 4 & 0 & 2 & 0 \\
Uninfected & 5 & 1 & 1 & 0 & 0 \\
& 1 & 0 & 1 & 0 & 0 \\
\end{tabular}

${ }^{*}$ Autolysis.

be used as an infection model to provide data about pathology and intracellular survival.

Similarities between invertebrate and mammalian humoral and cellular innate immune responses are exploited when using insects as virulence models. For example, G. mellonella possesses a cuticle that acts in the same physical barrier capacity as mammalian skin (Kemp \& Massey, 2007). Once the cuticle has been breached, G. mellonella induces a humoral response, producing soluble factors such as antimicrobial peptides (Mullett et al., 1993). In parallel with a humoral response, G. mellonella induces a cellular response to invading micro-organisms. Insect haemocytes phagocytose bacteria in a manner similar to that of mammalian neutrophils and produce a respiratory burst (Bergin et al., 2005). Thus, the response of $G$. mellonella to infection with $C$. jejuni is likely to have similarities to the response of humans.

In the initial experiment, larvae were infected with human C. jejuni isolates $11168-\mathrm{H}, 11168-\mathrm{O}, 81116,81176$ and $01 /$ 51. These were selected as they are well characterized in a

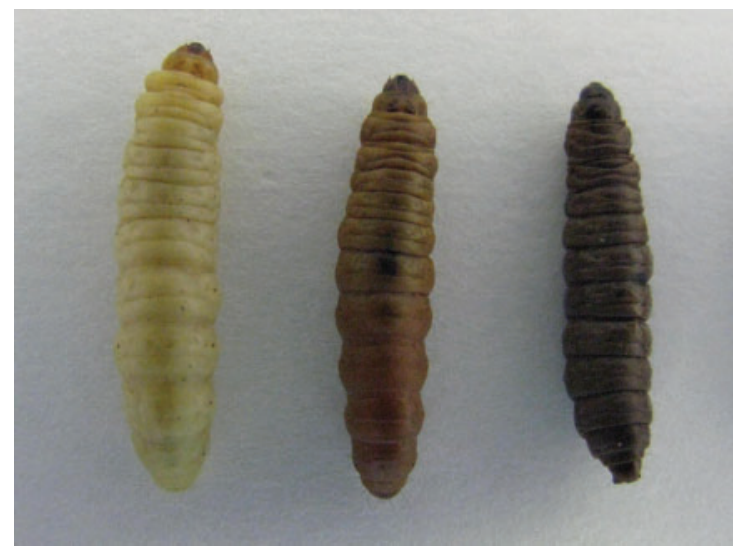

Fig. 3. Macroscopic evaluation of Wax Moth larvae following infection with C. jejuni: white, score 0 ; orange, score 1; black, score 3. number of other animal models; invasion and toxin data are also available for them. It would not have been possible to fix G. mellonella for all the strains used later on, as this would have been time-consuming and expensive with no guarantee of any further data.

Histopathology of infected larvae demonstrated that bacteria are found in the haemocoel and in the gut and that extensive tissue damage occurs in the latter. This pathology may be caused by haemocytes in the gut tissue, which have ingested bacteria circulating in the haemocoel and then produced responses such as the release of free radicals and peroxide, causing the visible tissue damage. The presence of pigmented nodules, which are aggregations of haemocytes around foreign bodies, indicates a vigorous immune response to infection (Lackie, 1980). The observed colour change in infected larvae correlating with the presence of bacteria in the body cavity is a product of melanogenesis; this process is thought to protect

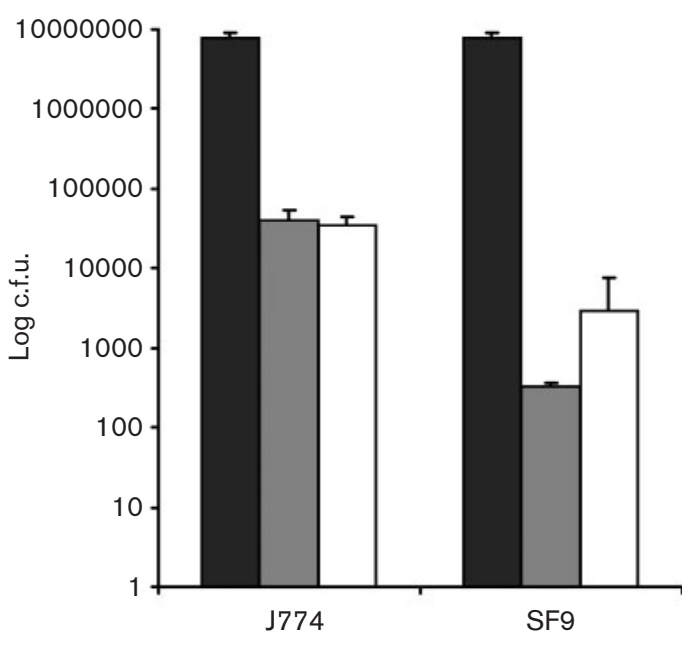

Fig. 4. Chart showing the mean numbers of C. jejuni $11168-\mathrm{H}$ recovered from J774.1A murine macrophages and SF9 insect cell line at $4 \mathrm{~h}$ (shaded bars) and $24 \mathrm{~h}$ (white bars) post-infection $(n=3) .0 \mathrm{~h}$ (black bars) represents the initial inoculum. 


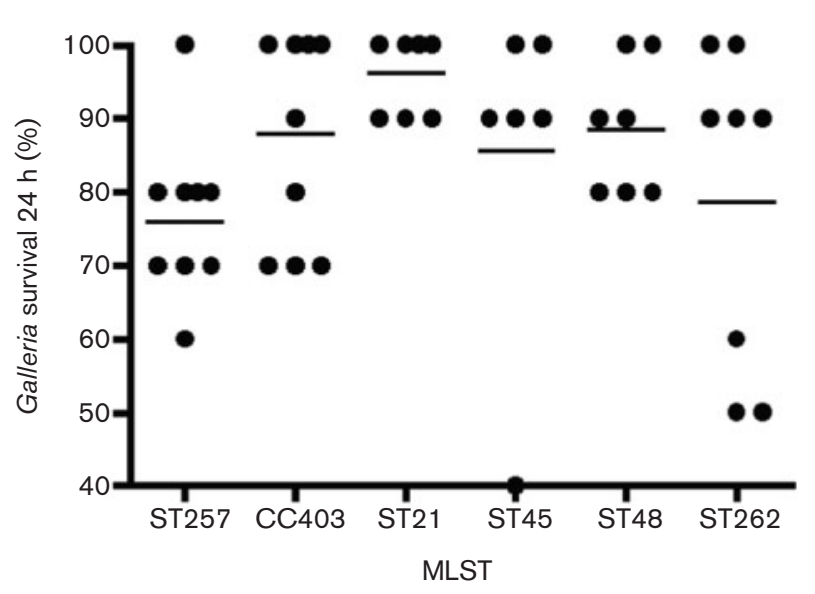

Fig. 5. Graph of G. mellonella survival following challenge with $C$. jejuni of different MLST types. Each data point represents the mean percentage larval survival $(n=10)$. Horizontal lines represent the mean for each MLST type.

endogenous tissues within the cavity from systemic damage resulting from pathogen killing (Nappi \& Christensen, 2005).

The bacteria observed in the larval sections were not identified, but were only present in Campylobacter infected larvae. The bacterial cells were coccoid rather than spiral; however, C. jejuni that has become intracellular converts rapidly from the spiral form to the coccoid form (Kiehlbauch et al., 1985). There is some debate about how this change affects the bacteria (Moore, 2001). Adaptation to the coccoid form is generally seen as a response to stress, such as starvation or oxidative stress (Harvey \& Leach, 1998). Some studies, such as that of Moran \& Upton (1986), have reported that the coccoid form is thus degenerative. However, it has also been reported that coccoid C. jejuni becomes viable but non-culturable, with the potential to still act as an infectious agent ( $\mathrm{He} \& \mathrm{Chen}$, 2010). To ascertain whether these coccoid cells were likely to be C. jejuni, a comparison was made between GFPtagged $C$. jejuni grown in broth overnight versus the same bacteria inoculated into G. mellonella and incubated for $3 \mathrm{~h}$. Under confocal microscopy, the fluorescing bacteria from broth were seen to be elongated, reflecting the normal spiral morphology of C. jejuni; the bacteria from the larval haemolymph were short and round like the coccoid bacteria seen in the larval sections. Haemolymph from PBS control larvae contained no fluorescing bacteria. This observation suggests that the coccoid bacteria are indeed C. jejuni.

Within the haemocoel, cell-associated and free bacteria were found. C. jejuni is primarily an extracellular pathogen; however, intracellular survival has been hypothesized to play an important role in its pathogenesis (Kiehlbauch et al., 1985; Hickey et al., 2005; Young et al., 2007). Reproducible in vitro infection models that mimic pathogenesis in vivo have been used to study $C$. jejuni intracellular survival in epithelial cells (De Melo et al., 1989; Watson \& Galán, 2008). However, reports of C. jejuni intramacrophage survival in vitro are conflicting. Some groups indicate that $C$. jejuni is killed by macrophages (Watson \& Galán, 2008); others suggest that the bacteria survive within the macrophage (Day et al., 2000; Hickey et al., 2005). In this study, bacterial infection of different cell lines was undertaken to establish whether there was a difference in response between mammalian macrophages and an insect cell line. It was uncertain as to whether $C$. jejuni would survive intracellularly in the SF9 insect cell line under tissue culture conditions. However, although the levels of $C$. jejuni recovered from the insect cell line were approximately ten times lower than those recovered from murine macrophages at $4 \mathrm{~h}$ post-infection, it is clear from the data presented here that the bacteria did invade the cells and survive within them.

The bacterial numbers recovered from the macrophages remained consistent between $4 \mathrm{~h}$ and $24 \mathrm{~h}$; there was survival within the macrophages. This is consistent with previous studies (Kiehlbauch et al., 1985; Hickey et al., 2005). However, there was a significant increase in C. jejuni recovered from the insect cell line at $24 \mathrm{~h}$ compared to $4 \mathrm{~h}$. Thus, it is possible that the bacteria not only survived within the cells, but also replicated.

These observations are consistent with the hypothesis that C. jejuni enters insect haemocytes during in vivo model infections of G. mellonella. This intracellular persistence may allow the bacteria to avoid, or at least reduce the impact of, host antimicrobial defences. Nevertheless, the fact that at least some bacteria provoked the formation of melanized nodules is not surprising as it has previously been shown that nodule formation is associated with phagocytosis (Dean et al., 2004).

C. jejuni strains can be classified by MLST complexes. A number of studies have sought to establish whether there is a link between MLST type and the development of postinfectious complications (Dingle et al., 2001; Nielsen et al., 2010; Islam et al., 2009). It was noted that the ST22 complex is over-represented in isolates from patients who have contracted Guillain-Barré syndrome; no GuillainBarré-related isolates have been shown to carry ST45, despite it being a common sequence type (Dingle et al., 2001; Nielsen et al., 2010). No sequence types have been found to be exclusive for clinical outcomes (Islam et al., 2009). This supports the findings of Manning et al. (2003), who studied a large number of $C$. jejuni isolates and found that in terms of MLST types, the populations of veterinary and human isolates overlapped; it was suggested that most veterinary sources should be considered reservoirs of pathogenic campylobacters. However, these studies did not assess whether bacteria from different MLST types exhibited different levels of virulence. Recent studies have suggested that there may be associations between $C$. jejuni MLST type and virulence factors (Habib et al., 2009; de 
Haan et al., 2010). We observed that when bacteria selected as representatives of major MLST groups were put through the G. mellonella model, MLST type 257 strains were significantly more virulent than the MLST type 21 set. MLST type 257 is mainly associated with poultry and clinical isolates. MLST type 21 is common in all foodproducing animals; the strains used here are also all of clonal complex (CC) 21, which is one of the four most common CCs in human disease. The reduced virulence of these isolates in the model may thus appear anomalous, but Habib et al. (2010) suggest that the abundant prevalence of C. jejuni of CC21 may be a result of its increased tolerance of stresses encountered during the human food chain. A less virulent but more stress-tolerant strain would thus be encountered more frequently than a more virulent strain that did not tolerate such stresses to the same extent. The convenience of the G. mellonella model allows for high throughput screening to assay for the differences in virulence. Such a model could provide preliminary data when considering food security issues.

This study has sought to further characterize G. mellonella as a model for $C$. jejuni infection, and suggests that, since the bacteria convert to a coccoid form once within the insect, it may be used to provide opportunities for further study of this morphological change. The model may also prove useful in investigating the in vivo intracellular survival of C. jejuni within macrophages, an area of some dispute. In particular, the model allows screening for natural variations in the virulence of $C$. jejuni field isolates, which would prove invaluable for tracking particularly virulent strains in the food chain.

\section{ACKNOWLEDGEMENTS}

We thank Peter Splatt (University of Exeter) for his technical assistance with confocal microscopy.

\section{REFERENCES}

Babakhani, F. K., Bradley, G. A. \& Joens, L. A. (1993). Newborn piglet model for campylobacteriosis. Infect Immun 61, 3466-3475.

Bergin, D., Reeves, E. P., Renwick, J., Wientjes, F. B. \& Kavanagh, K. (2005). Superoxide production in Galleria mellonella hemocytes: identification of proteins homologous to the NADPH oxidase complex of human neutrophils. Infect Immun 73, 4161-4170.

Champion, O. L., Karlyshev, A. V., Senior, N. J., Woodward, M. J., La Ragione, R. M., Howard, S. L., Wren, B. W. \& Titball, R. W. (2010). Insect infection model for Campylobacter jejuni reveals that O-methyl phosphoramidate has insecticidal activity. J Infect Dis 201, 776782.

Day, W. A., Jr, Sajecki, J. L., Pitts, T. M. \& Joens, L. A. (2000). Role of catalase in Campylobacter jejuni intracellular survival. Infect Immun 68, 6337-6345.

Dean, P., Potter, U., Richards, E. H., Edwards, J. P., Charnley, A. K. \& Reynolds, S. E. (2004). Hyperphagocytic haemocytes in Manduca sexta. J Insect Physiol 50, 1027-1036.

de Haan, C. P. A., Kivistö, R. \& Hänninen, M. L. (2010). Association of Campylobacter jejuni Cj0859c gene $(f s p A)$ variants with different $C$. jejuni multilocus sequence types. Appl Environ Microbiol 76, 69426943.

De Melo, M. A., Gabbiani, G. \& Pechère, J.-C. (1989). Cellular events and intracellular survival of Campylobacter jejuni during infection of HEp-2 cells. Infect Immun 57, 2214-2222.

Dingle, K. E., Van Den Braak, N., Colles, F. M., Price, L. J., Woodward, D. L., Rodgers, F. G., Endtz, H. P., Van Belkum, A. \& Maiden, M. C. J. (2001). Sequence typing confirms that Campylobacter jejuni strains associated with Guillain-Barré and Miller-Fisher syndromes are of diverse genetic lineage, serotype, and flagella type. J Clin Microbiol 39, 3346-3349.

Fox, J. G., Ackerman, J. I., Taylor, N., Claps, M. \& Murphy, J. C. (1987). Campylobacter jejuni infection in the ferret: an animal model of human campylobacteriosis. Am J Vet Res 48, 85-90.

Habib, I., Louwen, R., Uyttendaele, M., Houf, K., Vandenberg, O., Nieuwenhuis, E. E., Miller, W. G., van Belkum, A. \& De Zutter, L. (2009). Correlation between genotypic diversity, lipooligosaccharide gene locus class variation, and Caco-2 cell invasion potential of Campylobacter jejuni isolates from chicken meat and humans: contribution to virulotyping. Appl Environ Microbiol 75, 4277-4288.

Habib, I., Uyttendaele, M. \& De Zutter, L. (2010). Survival of poultryderived Campylobacter jejuni of multilocus sequence type clonal complexes 21 and 45 under freeze, chill, oxidative, acid and heat stresses. Food Microbiol 27, 829-834.

Harvey, P. \& Leach, S. (1998). Analysis of coccal cell formation by Campylobacter jejuni using continuous culture techniques, and the importance of oxidative stress. J Appl Microbiol 85, 398-404.

He, Y. \& Chen, C.-Y. (2010). Quantitative analysis of viable, stressed and dead cells of Campylobacter jejuni strain 81-176. Food Microbiol 27, 439-446.

Hickey, T. E., Majam, G. \& Guerry, P. (2005). Intracellular survival of Campylobacter jejuni in human monocytic cells and induction of apoptotic death by cytholethal distending toxin. Infect Immun 73, 5194-5197.

Humphrey, T., O’Brien, S. \& Madsen, M. (2007). Campylobacters as zoonotic pathogens: a food production perspective. Int $J$ Food Microbiol 117, 237-257.

Islam, Z., van Belkum, A., Wagenaar, J. A., Cody, A. J., de Boer, A. G., Tabor, H., Jacobs, B. C., Talukder, K. A. \& Endtz, H. P. (2009). Comparative genotyping of Campylobacter jejuni strains from patients with Guillain-Barré syndrome in Bangladesh. PLoS ONE 4, e7257.

Janssen, R., Krogfelt, K. A., Cawthraw, S. A., van Pelt, W., Wagenaar, J. A. \& Owen, R. J. (2008). Host-pathogen interactions in Campylobacter infections: the host perspective. Clin Microbiol Rev 21, 505518.

Jones, M. A., Marston, K. L., Woodall, C. A., Maskell, D. J., Linton, D., Karlyshev, A. V., Dorrell, N., Wren, B. W. \& Barrow, P. A. (2004). Adaptation of Campylobacter jejuni NCTC11168 to high-level colonization of the avian gastrointestinal tract. Infect Immun 72, 3769-3776.

Karlyshev, A. V., Linton, D., Gregson, N. A. \& Wren, B. W. (2002). A novel paralogous gene family involved in phase-variable flagellamediated motility in Campylobacter jejuni. Microbiology 148, 473480.

Kemp, M. W. \& Massey, R. C. (2007). The use of insect models to study human pathogens. Drug Discov Today Dis Models 4, 105-110.

Kiehlbauch, J. A., Albach, R. A., Baum, L. L. \& Chang, K.-P. (1985). Phagocytosis of Campylobacter jejuni and its intracellular survival in mononuclear phagocytes. Infect Immun 48, 446-451.

Lackie, A. M. (1980). Invertebrate immunity. Parasitology 80, 393412 . 
Manning, G., Dowson, C. G., Bagnall, M. C., Ahmed, I. H., West, M. \& Newell, D. G. (2003). Multilocus sequence typing for comparison of veterinary and human isolates of Campylobacter jejuni. Appl Environ Microbiol 69, 6370-6379.

Moore, J. E. (2001). Bacterial dormancy in Campylobacter: abstract theory or cause for concern? Int J Food Sci Technol 36, 593-600.

Moran, A. P. \& Upton, M. E. (1986). A comparative study of the rod and coccoid forms of Campylobacter jejuni ATCC 29428. J Appl Bacteriol 60, 103-110.

Mullett, H., Ratcliffe, N. A. \& Rowley, A. F. (1993). Analysis of immune defences of the wax moth, Galleria mellonella, with anti-haemocytic monoclonal antibodies. J Insect Physiol 39, 897-902.

Nappi, A. J. \& Christensen, B. M. (2005). Melanogenesis and associated cytotoxic reactions: applications to insect innate immunity. Insect Biochem Mol Biol 35, 443-459.

Newell, D. (2001). Animal models of Campylobacter jejuni colonization and disease and the lessons to be learned from similar Helicobacter pylori models. J Appl Microbiol 90, 57S-67S.
Nielsen, L. N., Sheppard, S. K., McCarthy, N. D., Maiden, M. C. J., Ingmer, H. \& Krogfelt, K. A. (2010). MLST clustering of Campylobacter jejuni isolates from patients with gastroenteritis, reactive arthritis and Guillain-Barré syndrome. J Appl Microbiol 108, 591-599.

Skirrow, M. B. (1977). Campylobacter enteritis: a "new" disease. BMJ 2, 9-11.

van Doorn, P. A., Ruts, L. \& Jacobs, B. C. (2008). Clinical features, pathogenesis, and treatment of Guillain-Barré syndrome. Lancet Neurol 7, 939-950.

Wassenaar, T. M., van der Zeijst, B. A., Ayling, R. \& Newell, D. G. (1993). Colonization of chicks by motility mutants of Campylobacter jejuni demonstrates the importance of flagellin A expression. J Gen Microbiol 139, 1171-1175.

Watson, R. O. \& Galán, J. E. (2008). Campylobacter jejuni survives within epithelial cells by avoiding delivery to lysosomes. PLoS Pathog 4, e14.

Young, K. T., Davis, L. M. \& DiRita, V. J. (2007). Campylobacter jejuni: molecular biology and pathogenesis. Nat Rev Microbiol 5, 665-679. 